\title{
Multi-agent Negotiation Computation in Agile Supply Chain
}

\author{
Yee Ming Chen \\ Department of Industrial Engineering and Management, Yuan Ze University, Taiwan
}

\begin{abstract}
This paper proposes a new approach for tackling the agile supply chain of identifying suitable supplier offers; evaluating the offers and choosing the best outsource fashion apparels in multi-agent negotiation. An integrated analytic hierarchy process (AHP) with multi-agent technique based multi-criteria decision-making methodology is then developed to consider both qualitative and quantitative factors in supplier selection. We focused on multi-agent negotiation mechanism including qualitative conditions which could enables automated negotiation on multiple attributes. Then, fuzzy membership function represented the buyer/seller's cognition for each condition such as quantity, cost, quality, and delivery for the outsourced fashion apparels. Finally, a case study in a fashion manufacturing company is given to demonstrate the potential of the methodology.
\end{abstract}

Keywords: - Multi-agent negotiation, Analytic hierarchy process, Agile supply chain management

\section{INTRODUCTION}

The Supply chain management is a business function which basically aims at organizing and synchronizing monitoring the use of the various resources distributed across the supply chain in order to optimize its response to customer orders and shareholders expectations for profitability [1,2]. Now days, many companies are facing constantly increasing competition stimulated by technological innovations, changing market environments and changing customer demands. Agility makes processes and organization individuals keep pace with the advanced technology and meets customer requirements in a relatively short period of time based on high quality products and services. The company and organization which is able to practice agility might have a dominant presence worldwide. The capabilities that an agile organization should have to be able to make appropriate response to change taking place in its business environment, are basically divided into four major categories. These are:

(1)Responsiveness: Which is the ability to identify changes and respond fast to supply chain.

(2) Competency: Which is the extensive set of abilities that provide productivity, efficiency, and effectiveness of activities towards the aims and goals of the company.

(3) Flexibility: Which is the ability to process different products and achieve different objectives with the same facilities.

(4) Quickness: Which is the ability to carry out tasks and operations in the shortest possible time.

Realizing agility is a business process and customer requirement, social, economic and political drivers result in increasing effects on the order fulfillment of on agile supply chain. Agile supply chain increasingly is choosing partnerships as a way to compete in fashion market place. Traditionally, vendors are selected from among many suppliers on their ability to meet the quality requirements, delivery schedule, and the price offered. In this approach, suppliers aggressively compete with each other and the relationship with buyer is usually adversarial. Entering agile supply chain era, the cooperation between buyer and supplier is the starting point to establish a successful agile supply chain management. The vendor selection is also called supplier selection from now on. Therefore, supplier selection and evaluation are very important to the success of the agile supply chain process [1]. The objective of this study is to develop an integrated analytic hierarchy process with multiagent negotiation computation, which will help to solve the supplier selection problems to obtain the lowest possible price by creating strong competition between suppliers, and negotiating with them. The supplier selection negotiation computation seems the most complex, since it requires evaluation and decision-making under uncertainty, based on multiple attributes of quantitative and qualitative nature, involving temporal and resource constraints, risk and commitment problems, varying tactics and strategies, domain specific knowledge and information asymmetries, etc. The negotiation process typically involves a sequence of interdependent activities - from partners' selection to enter the negotiation, through the negotiation per se to the execution of the agreed deal. Since supplier selection negotiation is of a special importance for agile supply chain management. The rest of the paper is organized as follows. The next section presents the influence factors affecting the supplier selection process and the integrated AHP with multi-agent negotiation based multiattribute decision-making methodology is then developed to consider both qualitative and quantitative factors in 
supplier selection. The details of the methodology are given in Section 3 and its application is explained through a case study in Section 4. Finally, the last section contains some conclusions and perspectives.

II.

\section{BRIEF REVIEW AND ANALYSIS OF AGILE SUPPLY CHAIN MANAGEMENT}

Traditional methodologies of the agile supply chain management for supplier selection process in research literature include the cost-ratio method, the categorical method, weighted-point evaluations, mathematical programming models and statistical or probabilistic approaches [3] [4]. A study by Vokurka looked at the supplier selection decision criteria used in buying different categories of products [5]. The myriad factors were grouped into performance criteria, economic criteria, integrative criteria and adaptive criteria. The advantage of the categorical method is to help structure the evaluation process in a clear and systematic way. However, a disadvantage with this approach is that typically it does not clearly define the relative importance of each criterion [6]. Weber et al. has compiled many articles in this area and he used a linear weighting model for supplier selection. Linear weighting models place a weight on each criterion and provide a total score for each supplier by summing up the supplier's performance on the criteria multiplied by these weights [2]. Mandal and Desmukh used an interpretive structural modeling for vendor selection [7]. In this study, Mandal developed an analytical framework, which combines qualitative and quantitative factors [8]. Another approach for supplier selection is the analytic hierarchy approach (AHP) [9]. In this study the AHP approach was employed to make the supplier selection decision. Therefore, we should first answer the following questions: (1) What supplier selection criteria to use? (2) How to use them? and (3) How to automatically trade offers and come to mutually acceptable agreement? The first question is relatively easy to answer. We should use a set of criteria that are well accepted. The second question is often ignored by researchers since they usually assign fixed weights to the criteria. The last question of automating negotiations also opens up a number of new possibilities. So, we combined AHP and fuzzy membership function into multi-agent negotiation computation. AHP deals with the traders' relative preference and satisfaction for offer and counter-offer. Meanwhile, we concentrate on the oneto-one case and develop an automated software agent for multi-attributes negotiations. Therefore, the approach could adapt and change the conditions for a deal agile supply chain management.

\section{METHODODOLOGY}

A fashion manufacturing company lies in an agile supply chain, which includes its suppliers, distributors, and final customers. Company will make decision in two phases: (a) to choose most favorable supplier(s) for various outsourced components to meet its supplier selection criteria and (b) to order various quantities, prices etc. from the chosen most favorable supplier to meet its production plan. The first phase was to apply decomposition-synthesis approach using AHP. At the second phase, mechanism is selection of preferred offer of negotiation agents. We first used linear programming to calculate buyer's (fashion manufacturing company) offer and then used the agents of buyer and chosen supplier to automatically negotiate several times. As a result, buyer and chosen supplier can get the final satisfying offers.

Phase I: Apply decomposition-synthesis approach using AHP

\section{Step I_1. Decompose problem}

The underlying multi-criteria decision-making problem is decomposed according to its main components. The overall goal of supplier selection is to achieve optimal supplier efficiency. The efficiency measure consists of four top level attributes, namely, assets, business criteria, cost, and delivery. Each attribute consists of a number of specific performance metrics, which are identified in next step. These attributes were determined from reviewing literature and using brainstorming method [11] [12] [13] [14].

\section{Step I_2. Define attributes of agile supply chain for supplier selection}

Supply Chain Council (SCC) constructed a descriptive framework called SCOR [15]. SCOR is a standard supply chain process reference model designed to embrace all industries. SCOR performance metrics are used as the second level attributes for supplier selection. The SCOR endorses 16 performance metrics which was shown in Table 1. 
Table 1 SCOR performance metrics

\begin{tabular}{|c|c|c|}
\hline $\begin{array}{l}\text { Top level } \\
\text { attribute }\end{array}$ & \multicolumn{2}{|l|}{ Second level performance } \\
\hline \multirow{4}{*}{ Assets } & Cash-to-cash cycle time (a1) & days \\
\hline & Inventory days of supply (a2) & days \\
\hline & Order quantity (a3) & units \\
\hline & Visitation to supplier facilities (a4) & $\%$ \\
\hline \multirow{6}{*}{$\begin{array}{c}\text { Business } \\
\text { Criteria }\end{array}$} & Performance history (b1) & $\%$ \\
\hline & Production flexibility (b2) & $\%$ \\
\hline & Quality performance (b3) & grades \\
\hline & Position in the industry and reputation (b4) & grades \\
\hline & EDI capability (b5) & $\%$ \\
\hline & Organization structure (b6) & grades \\
\hline \multirow{3}{*}{ Cost } & Price $(\mathrm{c} 1)$ & $\$$ \\
\hline & Logistics cost (c2) & $\$$ \\
\hline & Value-added productivity (c3) & grades \\
\hline \multirow{3}{*}{ Delivery } & Supply chain response time (d1) & days \\
\hline & Delivery lead time $(\mathrm{d} 2)$ & days \\
\hline & Fill rate $(\mathrm{d} 3)$ & $\%$ \\
\hline
\end{tabular}

These performance metrics above are adopted as the standard attributes for evaluating a supplier's performance.

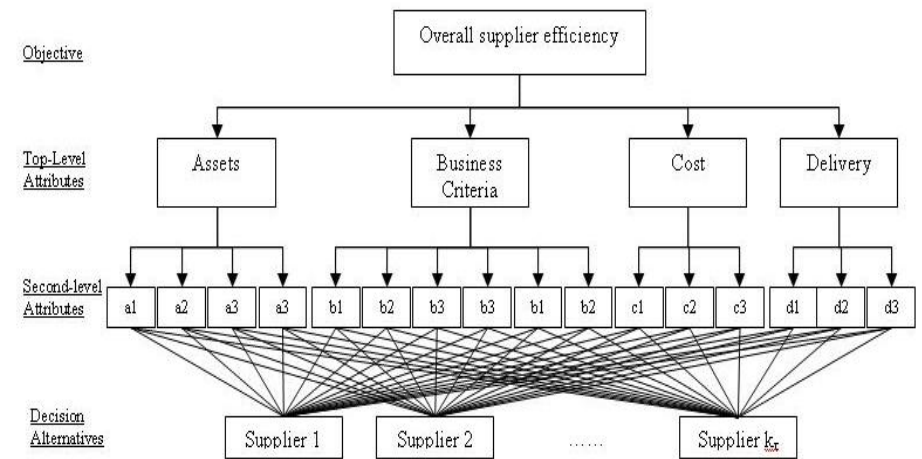

Figure 1 AHP hierarchy of agile supply chain for suppliers selection

\section{Step I_3. Design the hierarchy}

The hierarchy consists of the overall goal, top level attributes, second level attributes (performance metrics), sub-level (could have several levels), and the decision alternatives. Figure 1 schematically illustrates the proposed hierarchy based on SCOR metrics.

\section{Step I_4. Construct pair-wise comparison matrix}

Fashion manufacturing company and suppliers used their preference to decide linguistic value of each attribute to describe how much more important the $\mathrm{i}$-th attribute is than the $\mathrm{j}$-th attribute then construct comparison matrix of each attribute.

The comparison matrix of company A for product $r$ determining outsourced component Os is shown below by linguistic attribute values, $a_{i j} \in[1,3,5,7,9]$.

$\mathrm{O}_{\mathrm{s}}=\left\lfloor\mathrm{a}_{\mathrm{ij}}\right\rfloor_{\mathrm{n} \times \mathrm{n}}, \mathrm{n}$ represents the number of attributes

$a_{i j}=\left\{\begin{array}{rl}1 & , i=j \\ 3,5,7,9 & , \text { otherwise }\end{array}, a_{j i}=\frac{1}{a_{i j}}\right.$

Step I_5. Normalized the comparison matrix

This step was to normalize each element of the comparison matrix in the formula 1. 
N_O $=\left[\begin{array}{cccc}\frac{a_{11}}{\sum_{i=1}^{n} a_{i 1}} & \frac{a_{12}}{\sum_{i=1}^{n} a_{i 2}} & \cdots & \frac{a_{1 n}}{\sum_{i=1}^{n} a_{i n}} \\ \vdots & & \ddots & \vdots \\ \frac{a_{n 1}}{\sum_{i=1}^{n} a_{i 1}} & \cdots & & \frac{a_{n n}}{\sum_{i=1}^{n} a_{i n}}\end{array}\right]$

Step I_6. Selection of optimal supplier by overall weights

$C=\left[c_{i j}\right]=\left[\begin{array}{c}\frac{a_{11}}{\sum_{i=1}^{n} a_{i 1}}+\frac{a_{12}}{\sum_{i=1}^{n} a_{i 2}}+\cdots+\frac{a_{1 n}}{\sum_{i=1}^{n} a_{i n}} \\ \vdots \\ \frac{a_{11}}{\vdots}+\frac{a_{12}}{\sum_{i=1}^{n} a_{i 1} a_{i 2}}+\cdots+\frac{a_{1 n}}{\sum_{i=1}^{n} a_{i n}} \\ n\end{array}\right]$

$X=\left[x_{1} x_{2} \cdots x_{n}\right]^{\mathrm{T}}=N_{-} O_{s} \cdot C$

We first calculated the average vector $\mathrm{C}$ which is the average of each element in row i of N_ $O_{s}$. Then using $N_{-} O_{s} \cdot C$ to form the overall weights $\mathrm{X}$.

Step I_7. Consistency check

After step I_5 and I_6, we needed to check consistency in the comparison matrix. See if the consistency ratio (CR) was satisfactory.

$r=\frac{1}{n} \sum_{i=1}^{n} \frac{x_{i}}{c_{i}}$

$C I=\frac{r-n}{n-1}, \quad C R=\frac{C I}{R I(\text { RandomIndex })}$

If $\mathrm{CR}<0.1$, the degree of consistency is satisfactory, but if $\mathrm{CR}>0.1$, serious inconsistencies may exist, and the AHP may not yield meaningful results. Then we back to consider another attribute.

Phase II: Multi-agent negotiation computation between company and the chosen most favorable supplier

\section{Step II_1. Fuzzy membership function}

Assume that each attribute had its range that can be changed by the buyer. In this paper, we adopted triangular membership function to transfer the value of attributes into fuzzy value (FV) graded from 0 to 1 . Table 2 below is some abbreviations about the definitions. And the average of fuzzy value of all attributes represented buyer/seller's satisfaction degrees (SD).

\section{Step II_2. Determine initial offers of buyer}

Due to buyer wanted the average satisfaction degree to improve higher. In this step, we used linear programming to calculate the initial offers of buyer using the initial offers of seller.

Table 2 Notation

\begin{tabular}{|c|l|}
\hline \multicolumn{2}{|c|}{ Notation } \\
\hline IOB & Initial offers of Buyer \\
\hline IOS & Initial offers of Seller \\
\hline FVB & Fuzzy value of Buyer \\
\hline FVS & Fuzzy value of Seller \\
\hline SDB & Satisfaction degree of Buyer \\
\hline SDS & Satisfaction degree of Seller \\
\hline
\end{tabular}

$\mathrm{SDB}=$ average $($ sum of all FVB)

SDS = average (sum of all FVS) 


\section{Step II_3. Determine negotiation bargain strategy of buyer and seller}

As we decided the most suitable supplier, the buyer still hoped that satisfaction can improve, so the chosen supplier and the buyer needed to negotiate the offers of them. And the negotiation computation used multi-agent based bargain strategy to let both sides make concessions with each attribute. And the objective of bargain strategy was to find out the most approaching satisfaction between buyer and seller (supplier/company A).

\section{Step II_4. Multi-agent negotiation process}

According to step II_2 in this phase, we firstly chose the biggest difference of attributes mi between buyer and seller as major factor to negotiate. First started with bargain strategy of buyer and seller, then their agents began to change values of each attributes. Until the multi-agent achieved consensus of all attributes then negotiation would stop, and obtain the satisfying offers for both sides.

\section{CASE STUDY IMPLEMENTATION}

To demonstrate proposed multi-agent computation for supplier selection in agile supply chain, we used build-to-order (BTO) fashion manufacturing company in agile supply chain as our case. In order to maintain the confidentiality of the firm utilized in the case illustration, the fashion manufacturing company is referred to as company A. It is assumed that only three potential suppliers are qualified to supply the outsourced pattern making. So, in this study, three international suppliers of company A will be evaluated and named as supplier 1 (Taiwan), supplier 2 (Vietnam), and supplier 3 (Indonesia). Supplier 1 is a famous outsourcing firm which is good at ODM. Supplier 2 emphasizes its quality and makes the products to the best. And Supplier 3 is wellknown on its production rate. After knowing the information of suppliers, we started to progress of our computation step by step.

The first phase was to establish the comparison matrix of attributes of apparel and fashion product manufacturing company and suppliers. First of this phase, due to the discussion results of the company and the suppliers, we considered quantitative and qualitative conditions based on assets, business criteria, cost, and delivery four top level attributes. The second level employed 16 performance metrics with respective to top level attributes. In this case, there were three suppliers to select, and we proposed four attributes to compare the offers of each supplier. After knowing the suppliers' offers, the managers of apparel and fashion product manufacturing company need to firstly prioritize the performance metrics. This is done by using pair-wise comparison with Saaty's 1-9 scales. To facilitate the Phase I steps calculation, Matlab ${ }^{\circledR}$ programming developed and executed in this study. After repeating this calculation for all of the 16 attributes, all of the overall weights were computed as the Table 4.

Table 4 All overall rating weights in Phase II

\begin{tabular}{|c|c|c|c|c|c|}
\hline $\begin{array}{l}\text { Top Level } \\
\text { Attributes }\end{array}$ & $\begin{array}{c}\text { AHP weights } \\
\text { (Ci) }\end{array}$ & $\begin{array}{l}\text { Second Level } \\
\text { Attributes }\end{array}$ & $\begin{array}{l}\text { AHP weights } \\
\text { (Cai) }\end{array}$ & $\begin{array}{c}\text { Decision } \\
\text { Alternatives }\end{array}$ & $\begin{array}{l}\text { AHP weights } \\
\text { (Csi) }\end{array}$ \\
\hline \multirow{12}{*}{ Assets } & \multirow{12}{*}{0.078381} & \multirow{3}{*}{ a1 } & \multirow{3}{*}{0.03824} & Supplier 1 & 0.02371 \\
\hline & & & & Supplier 2 & 0.00527 \\
\hline & & & & Supplier 3 & 0.00814 \\
\hline & & \multirow{3}{*}{ a2 } & \multirow{3}{*}{0.02715} & Supplier 1 & 0.004755 \\
\hline & & & & Supplier 2 & 0.02004 \\
\hline & & & & Supplier 3 & 0.00286 \\
\hline & & \multirow{3}{*}{ a3 } & \multirow{3}{*}{0.00470} & Supplier 1 & 0.00307 \\
\hline & & & & Supplier 2 & 0.00169 \\
\hline & & & & Supplier 3 & 0.00093 \\
\hline & & \multirow{3}{*}{ a4 } & \multirow{3}{*}{0.01279} & Supplier 1 & 0.00250 \\
\hline & & & & Supplier 2 & 0.006769 \\
\hline & & & & Supplier 3 & 0.003898 \\
\hline \multirow{9}{*}{$\begin{array}{l}\text { Business } \\
\text { Criteria }\end{array}$} & \multirow{9}{*}{0.29014} & \multirow{3}{*}{ b1 } & \multirow{3}{*}{0.03584} & Supplier 1 & 0.00854 \\
\hline & & & & Supplier 2 & 0.02235 \\
\hline & & & & Supplier 3 & 0.00495 \\
\hline & & \multirow{3}{*}{ b2 } & \multirow{3}{*}{0.08030} & Supplier 1 & 0.01846 \\
\hline & & & & Supplier 2 & 0.05203 \\
\hline & & & & Supplier 3 & 0.00981 \\
\hline & & \multirow{3}{*}{ b3 } & \multirow{3}{*}{0.14636} & Supplier 1 & 0.08136 \\
\hline & & & & Supplier 2 & 0.01322 \\
\hline & & & & Supplier 3 & 0.051787 \\
\hline
\end{tabular}




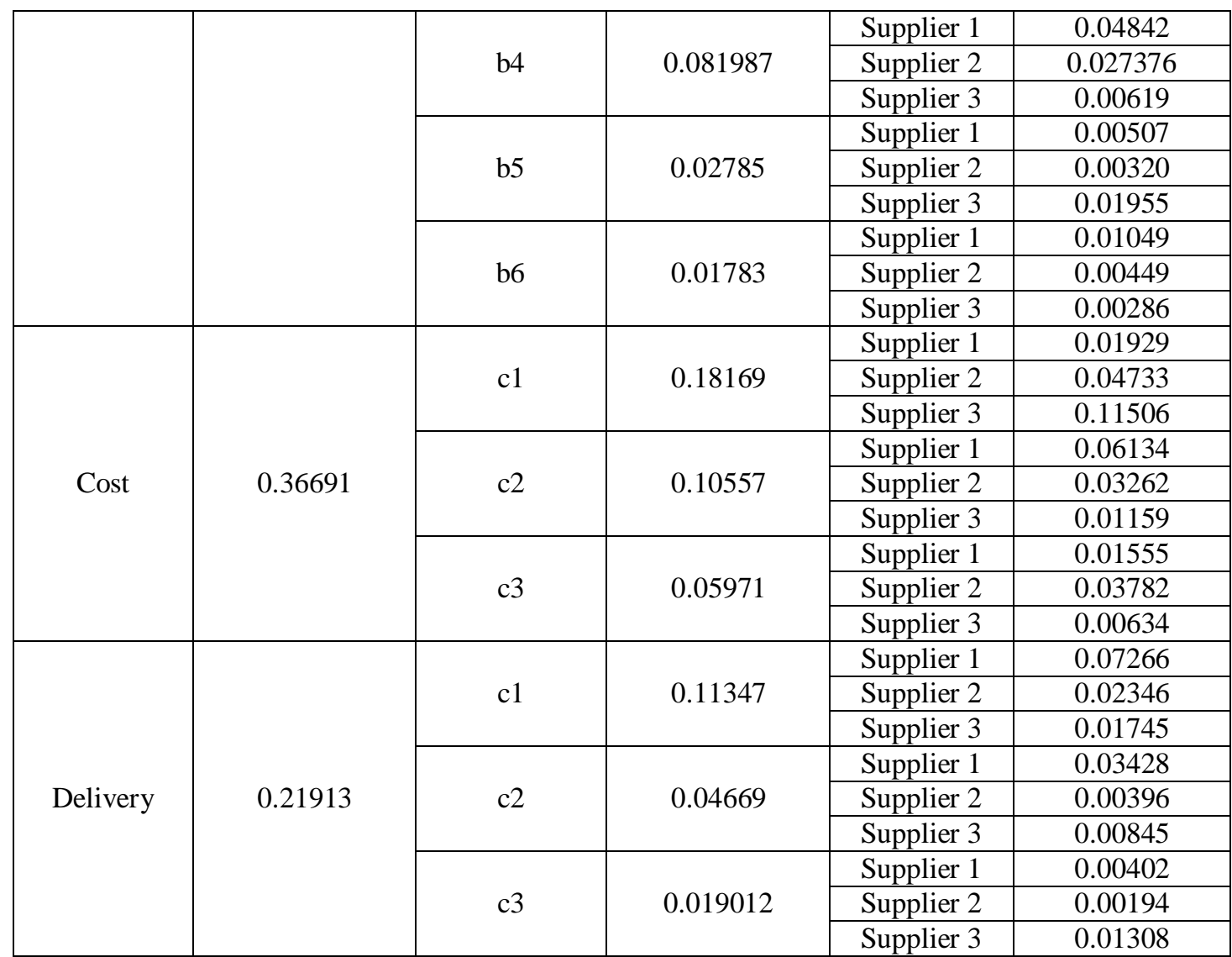

Based on the results of Table 4, the final rank of the outsourced pattern maker can be calculated by using the formula 11, and the supplier selection results are shown in Table 5.

Total weights of Supplier i $=\mathrm{CA}^{*} \mathrm{Ca} 1^{\circ} \mathrm{Csi}+\ldots+\mathrm{CC}^{\cdot} \mathrm{Cc} 3^{\circ} \mathrm{Csi}$

Table 5 Supplier selection results

\begin{tabular}{|l|l|}
\hline \multicolumn{2}{|c|}{ Final Rank } \\
\hline Supplier 1 & 0.51317 \\
\hline Supplier 2 & 0.28395 \\
\hline Supplier 3 & 0.32349 \\
\hline
\end{tabular}

Because supplier 1 is the highest weights of the result of overall weights in Phase I, the buyer chose it as the optimal trader. Then, next negotiation process will be executed between buyer and supplier 1.

Phase II: Multi-agent negotiation computation between company and the chosen most favorable supplier in agile supply chain

\section{Step II_1. Fuzzy membership function}

In this phase, each negotiation agent offers their negotiation conditions reflecting their relative satisfaction for a deal. Where, a deal was composed of quantitative conditions such as quantity, cost, quality, and delivery. However, the fuzzy value for these conditions will be changed by fuzzy membership functions such as satisfaction degree. The software agent generates assignment value for it. The framework system then asked the user whether it is accept or not and further asked satisfaction degrees for each value of each attribute.

The workload of the above method is heavy if all possible combinations of many attributes need to be explored. However, it rarely happens because in the practice negotiations do not exist among an arbitrary combination of attributes and so human users usually tradeoffs specific attributes respectively.

\section{Step II_2. Determine initial offers of buyer}

When Supplier 1 was chosen, the offers needed to be negotiated between Supplier 1 and apparel and fashion product manufacturing company wanted to improve satisfaction degree from 0.6815 to 0.947 . So this step used linear programming to achieve this objective. At Table 6, we can find the fuzzy value of attribute 
“Quality” between seller and buyer both was 1 which means this component's quality was assured to keep high. Therefore we didn't need to negotiate this item.

Table 6 The initial offers of the seller and the buyer

\begin{tabular}{|c|c|c|c|c|c|}
\hline \multicolumn{3}{|c|}{ Seller ( Supplier 1 ) } & \multicolumn{3}{c|}{ Buyer ( Fashion Company ) } \\
\hline & IOS & FVS & & IOB & FVB \\
\hline Quantity & 530 & 0.46 & Quantity & 750 & 0.79 \\
\hline Cost & 18 & 0.92 & Cost & 15 & 0.97 \\
\hline Quality & 6 & 0.91 & Quality & 7 & 0.95 \\
\hline Delivery & 11 & 0.78 & Delivery & 15 & 0.86 \\
\hline SDS & & 0.81 & SDB & & 0.94 \\
\hline
\end{tabular}

StepII_3. Determine negotiation bargain strategy of buyer and seller

In this step, we first set the bargain strategy of seller and buyer then we can use agents of both sides to negotiate.

\section{Step II_4. Multi-agent negotiation computation process}

After deciding the bargain strategy, the agents of buyer and seller stood for both sides to start negotiating. The objective was to achieve the consensus as high as the satisfaction degree was.

In Table 6, we could find the attribute "Quantity" had the bigger difference than others. Initial offers of Supplier 1 only provided 530 units, but the manufacturer wanted it can reach 750 units. So their agents started to binegotiate.

The final offers of both sides were shown in Table 7. The satisfaction degree finally reached 0.915 from multiagent negotiation computation between the company and Supplier 1.

Table 7 The final result between buyer and seller

\begin{tabular}{|c|c|c|}
\hline \multicolumn{3}{|c|}{ Final offers } \\
\hline quantity & 740 & 0.812 \\
\hline cost & 16 & 0.94 \\
\hline quality & 6 & 0.98 \\
\hline delivery & 14 & 0.92 \\
\hline SD & & 0.915 \\
\hline
\end{tabular}

Since the supplier was chosen as the partner of the company, the interaction of both sides was important. So two of them need to negotiate and achieve a win-win situation.

\section{CONCLUSION}

Supplier evaluation is very important to the success of a fashion manufacturing company in agile supply chain. This is because of the cost and quality of fashion apparels and services sold is directly related to the cost and quality of goods and services purchased. Therefore, purchasing and supplier selection has an important role in the agile supply chain management. Sellers and buyers in internet-based agile supply chain through negotiations have significant impact on supplier selection and partners' profit. In this study, the integrated analytic hierarchical process with multi- has been proposed as a potential tool for analyzing and evaluating suppliers in the agile supply chain. Using the AHP main and sub attributes for supplier selection were clearly identified and the problem was structured systematically. Therefore, this paper is also attempt to develop how to elicit the user's bargain strategies in order for his autonomous agent to negotiate on their behalf. We would try also to enhance our decision support system with software agent techniques to enable managers comparing different solutions and making more rigorous decisions in the feature work.

\section{REFERENCES}

[1] K. S. Bhutta and F. Huq, Supplier selection problem: a comparison of the total cost of ownership and analytic hierarchy process approaches, 2002 .

[2] C. A. Weber, J. R. Current and W. C. Benton, Vendor selection criteria and methods. European Journal of Operational Research, 50, 1991, pp,2-18

[3] H. Yan, Z. Yu and T. C. E. Cheng, A Strategic model for supply chain design with logical constraints: formulation and solution. Computers \& Operations Research. September, 2003, pp. 1-21.

[4] R. C. Oliveira and J. C. Lourenço, A multicriteria model for assigning new orders to service suppliers, European Journal of Operational Research. 2002, pp.390-399. 
[5] J. R. Vokurka, J. Choobineh and L. Vadi, A prototype expert system for the evaluation and selection of potential suppliers, International Journal of Operations \& Production Management, 16(12), 1996, pp. 106-127.

[6] C. Muralisharan, N. Anantharaman and S. G. Deshmukh, A multi-criteria group decision making model for supplier rating. The Journal of Supply Chain Management. 2012, pp. 22-33.

[7] A. Mandal and S. G. Deshmukh, Vendor selection using interpretive structural modeling. International Journal of Operations \& Production Management. 14(6), 1994, pp. 52-59.

[8] J. Liu, F. Y. Ding and V. Lall, Using data envelopment analysis to compare suppliers for supplier selection and performance improvement. Supply Chain Management: An International Journal, 5(3), 2010, pp. 143-150.

[9] R. Narasimhan, S. Talluri and D. Mendez, Supplier evaluation and rationalization via data envelopment analysis: An empirical examination. The Journal of Supply Chain Management, 2009, pp. 28-35.

[10] K. Jiang and E. M. Wicks, Integrated investment justification approach for cellular manufacturing systems using activity-based costing and the analytic hierarchy process. Journal of Engineering Valuation and Cost Analysis , 2 (4), 2010, pp.271-284.

[11] M. Braglia, and A. Petroni, A quality assurance-oriented methodology for handling trade - offs in supplier selection. International Journal of Physical Distribution \& Logistics Management, 30(2), 2011, pp. 96-111.

[12] M. C. Y. Tam and V. M. R. Tummala, An application of the AHP in vendor selection of a telecommunication system. Omega, 29, 2001,, pp.171-182.

[13] C. Masella and A. Rangone, A contingent approach to the design of vendor selection systems for different types of co-operative customer/supplier relationship. International Journal of Operations \& Production Management, 20(1), 2009, pp. 70-84.

[14] SCC, Overview of the SCOR Model V2.0, (1999) Supply Chain Council, Inc., http://www.supply chain.org.

[15] P. T. Steel and Beasor, Business negotiation: A practical workbook ( Gower Publishing Limited, 1999). 